Article

\title{
Ultrasound-Assisted Extraction of Total Flavonoids from Pteris cretica L.: Process Optimization, HPLC Analysis, and Evaluation of Antioxidant Activity
}

\author{
Mengyang Hou ${ }^{1,2}$, Wenzhong $\mathrm{Hu}^{2,3, *}$, Aosheng Wang ${ }^{2,3}$, Zhilong Xiu ${ }^{1,2}$, Yusheng Shi ${ }^{2,3}$, \\ Kexin Hao ${ }^{2,3}$, Xingsheng Sun 2,3, Duo Cao ${ }^{4}$, Ruishan Lu ${ }^{2,3}$ and Jiao Sun 2,3 \\ 1 School of Bioengineering, Dalian University of Technology, Dalian 116024, China; \\ mengyanghou@yahoo.com (M.H.); zhlxiu@dlut.edu.cn (Z.X.) \\ 2 Key Laboratory of Biotechnology and Bioresources Utilization, Ministry of Education, Dalian 116600, China; \\ jnwangaosheng@sina.com (A.W.); shiyusheng@dlun.edu.cn (Y.S.); haokex@sina.com (K.H.); \\ sunxingsheng106@sina.com (X.S.); lrskarma@163.com (R.L.); sunjiao820@sina.com (J.S.) \\ 3 College of Life Science, Dalian Minzu University, Dalian 116600, China \\ 4 College of Life Sciences, Yanan University, Yanan 716000, China; caoduo2013@163.com \\ * Correspondence: wenzhongh@sina.com; Tel.: +86-135-9116-2665
}

Received: 31 August 2019; Accepted: 17 September 2019; Published: 24 September 2019

\begin{abstract}
In the present work, the ultrasonic-assisted extraction (UAE) of total flavonoids (TF) from Pteris cretica L. was optimized by response surface methodology (RSM) on the basis of a single-factor experiment. The optimized UAE parameters were as follows: Ethanol concentration 56.74\%, extraction time $45.94 \mathrm{~min}$, extraction temperature $74.27^{\circ} \mathrm{C}$, and liquid/solid ratio $33.69 \mathrm{~mL} / \mathrm{g}$. Under the optimized conditions, the total flavonoids yield (TFY) was $4.71 \pm 0.04 \%$, which was higher than that obtained by heat reflux extraction (HRE). The extracts were further analyzed by HPLC, and five major flavonoids, including rutin, quercitrin, luteolin, apigenin, and luteolin-7-O-glucoside, were identified and quantified. Furthermore, the results of the antioxidant test showed that the TF extract obtained under optimized UAE conditions exhibited good 2,2-diphenyl-1-picrylhydrazyl radical (DPPH•) and 2,2-azino-bis(3-ethylbenzothiazoline-6-sulfonic acid) radical $\left(\mathrm{ABTS}^{+} \bullet\right.$ ), nitric oxide radical (NO•) scavenging activities, and ferrous ion $\left(\mathrm{Fe}^{2+}\right)$ chelating capacity, with $\mathrm{IC}_{50}$ values of $74.49,82.92,89.12$, and $713.41 \mu \mathrm{g} / \mathrm{mL}$, respectively. Results indicated that the UAE technique developed in this work was an efficient, rapid, and simple approach for the extraction of flavonoids with antioxidant activity from P. cretica.
\end{abstract}

Keywords: Pteris cretica L.; flavonoids; ultrasonic-assisted extraction; optimization; response surface methodology; HPLC analysis; antioxidant activity

\section{Introduction}

Pteris cretica L., a perennial evergreen herb, belongs to the genus Pteris (Pteridaceae). The genus Pteris, geographically distributed over the tropical and subtropical regions of the world, consists of approximately 250 species, many of which have been cultivated for ornamental, culinary, and medicinal purposes [1,2]. Historically, several species of the genus Pteris have been used as folk medicine to treat burn injuries, indigestion, diarrhea, furuncles, eczema, apoplexy, jaundice, snakebites, and hemorrhages in China [3,4]. Due to the outstanding medicinal potential, modern investigations on the Pteris species have been performed extensively, which reveal that these plants contain various bioactive components, including flavonoids [5-7], sesquiterpenoids [3,8,9], and diterpenoids [9-11]. Flavonoids isolated from plants of this genus, including kaempferol, quercetin, rutin, apigenin, luteolin, and luteolin 7-O-sophoroside, especially contribute to various pharmacological effects, such as antibacterial [12], antioxidant [13], and anti-benign prostatic hyperplasia [14] potentials. 
As is known to all, extraction is a preliminary step in phytochemical research, which is also a necessary step in pharmaceutical research. Conventional extraction methods, including maceration, decoction, heat reflux, and Soxhlet extraction, are time-consuming, costly, and inefficient [15]. Fortunately, ultrasonic-assisted extraction (UAE) makes up for those shortcomings because the cavitation, vibration, crushing, and mixing effects in media produced by ultrasound can break the cell wall and increase the mass transfer process effectively [16]. In addition, UAE can not only avoid the heat-induced destruction of bioactive ingredients, but also helps to improve the safety of products [17]. Hence, UAE as an alternative technique has been widely used for the extraction of natural bioactive compounds, especially flavonoids, for instance, flavonoids from Medicago sativa Linn [18], Ampelopsis grossedentata leaves [19], and Olea europaea leaves [20]. To the best of our knowledge, research on the extraction of flavonoids from P. cretica have not been reported.

Admittedly, extraction yield and pharmacological action depend greatly on the comprehensive effect of several various factors, including the extraction method, solvent type, extraction time, extraction temperature, $\mathrm{pH}$, and liquid/solid ratio [21]. Therefore, to maximize the extraction yield of bioactive substances and pharmacological effects, optimization of the extraction process is quite essential. Recently, response surface methodology (RSM) as an advanced chemometric tool has been frequently applied to the optimization of the extraction process [22]. RSM design can reduce the number of experimental trials, resulting in lower reagent consumption and less laboratory work. Additionally, RSM design yields a mathematical model to account for the reciprocal influence of various independent variables [23]. Box-Behnken design (BBD), one type of RSM, is easier to interpret and perform in comparison with other designs [24].

The present study is an attempt to establish an efficient UAE technique for total flavonoids from P. cretica. First, the effects of four independent variables, including ethanol concentration, extraction time, extraction temperature, and liquid/solid ratio, on the yield of total flavonoids were investigated. Second, the reciprocal actions of independent variables were investigated followed by the optimization of the UAE process using RSM. Third, a heat reflux extraction experiment was carried out to verify the efficiency of the UAE method developed. Fourth, a comparison of flavonoid profiles of the extracts obtained by UAE under optimized conditions and heat reflux extraction (HRE) was performed by HPLC. In addition, the antioxidant activity of extracts obtained by optimized UAE was evaluated by 2,2-diphenyl-1-picrylhydrazyl radical (DPPH•), 2,2-azino-bis(3-ethylbenzothiazoline-6-sulfonic acid) radical $\left(\mathrm{ABTS}^{+} \bullet\right)$, nitric oxide radical $(\mathrm{NO} \bullet)$ scavenging activities, and $\mathrm{Fe}^{2+}$ chelating activity.

\section{Materials and Methods}

\subsection{Chemicals and Reagents}

Rutin, quercetin, luteolin, apigenin, and luteolin-7-O-glucoside standards were obtained from Shanghai Yuanye Bio-Technology Co., Ltd. (Shanghai, China). HPLC grade trifluoroacetic acid (TFA) and methanol were obtained from Aladdin Reagent Co., Ltd. (Shanghai, China). Ascrobic acid, 2,2-diphenyl-1-picrylhydrazyl (DPPH) and 2,2-azino-bis(3-ethylbenzothiazoline-6-sulfonic acid) (ABTS), ethylenediaminetetraacetic acid disodium salt (EDTA-2Na), sodium nitroprusside (SNP), potassium persulfate $\left(\mathrm{K}_{2} \mathrm{~S}_{2} \mathrm{O}_{8}\right)$, and trolox were obtained from Sigma-Aldrich (St. Louis, MO, USA). Other chemicals used (analytical grade) were bought from Kemio Chemical Reagent Co., Ltd. (Tianjin, China).

\subsection{Plant Material}

P. cretica was collected from Kunming City, Yunnan Province, China. A voucher specimen (FWJ-20180301) was deposited in the College of Life Science, Dalian Minzu University, Dalian, China. The plant material was dried under natural ventilation until reaching constant weight. The plant material was then powdered and stored in an air-tight container for further use. 


\subsection{Optimization of UAE of TF from P. cretica}

\subsubsection{Single-Factor Experiments}

The UAE of TF from $P$. cretica was performed in a water-bath sonicator (KQ5200DE, $40 \mathrm{kHz}$ frequency and $200 \mathrm{~W}$ nominal power, Kunshan Ultrasonic Instrument Co., Jiangsu, China). To study the influence of ethanol concentration on the total flavonoids yield (TFY), $5.0 \mathrm{~g}$ of pretreated samples were placed into glass conical flasks $(250 \mathrm{~mL}$ ) and soaked with ethanol solvents (varying from 30-80\%, $v / v$ ), the time for extraction was set at $30 \mathrm{~min}$, the temperature applied for extraction was set at $70{ }^{\circ} \mathrm{C}$, and the liquid/solid ratio was set at $30 \mathrm{~mL} / \mathrm{g}$. To select the optimum extraction time, different extraction times $(10,20,30,40,50$, and $60 \mathrm{~min})$ were tested under the conditions of ethanol concentration $60 \%$, extraction temperature $70{ }^{\circ} \mathrm{C}$, and liquid/solid ratio $30 \mathrm{~mL} / \mathrm{g}$. To choose the best extraction temperature, different extraction temperatures $\left(40,50,60,70,80\right.$, and $\left.90{ }^{\circ} \mathrm{C}\right)$ were studied under the following conditions: Ethanol concentration $60 \%$, extraction time $40 \mathrm{~min}$, and liquid/solid ratio $30 \mathrm{~mL} / \mathrm{g}$. Finally, the effect of liquid/solid ratios of $15,20,25,30,35$, and $40 \mathrm{~mL} / \mathrm{g}$ on the extraction yield was evaluated under the following conditions: Ethanol concentration $60 \%$, extraction time $40 \mathrm{~min}$, and extraction temperature $70{ }^{\circ} \mathrm{C}$. After each UAE, the extraction solution was filtered, and the sample residue was re-extracted twice under the same extraction conditions. The combined extractive solution was then concentrated in vacuo and the extract was stored at $-20^{\circ} \mathrm{C}$ for further analysis.

\subsubsection{RSM Design}

Based on the results of single-factor experiments, the UAE of TF from P. cretica was further optimized by RSM. In this work, the BBD with four variables (ethanol concentration $X_{1}$, extraction time $X_{2}$, extraction temperature $X_{3}$, and liquid/solid ratio $\left.X_{4}\right)$ at three levels $(-1,0,1)$ was carried out to evaluate the effect between every two variables on the response value (TFY Y). The BBD procedure of RSM resulted in a total of 29 randomized experiments, and a quadratic model used to analyze experimental data was shown as follows:

$$
Y=\alpha_{0}+\sum_{\mathrm{i}=1}^{4} \alpha_{\mathrm{i}} X_{\mathrm{i}}+\sum_{\mathrm{i}=1}^{4} \alpha_{\mathrm{ii}} X_{\mathrm{i}}^{2}+\sum_{\mathrm{i}=1}^{3} \sum_{\mathrm{j}=\mathrm{i}+1}^{4} \alpha_{\mathrm{ij}} X_{\mathrm{i}} X_{\mathrm{j}}
$$

where $Y$ is the response value; $\alpha_{0}$ refers to the intercept; $\alpha_{\mathrm{i}}, \alpha_{\mathrm{ii}}$, and $\alpha_{\mathrm{ij}}$ refer to the linear, quadratic, and interactive coefficients, respectively; $X_{\mathrm{i}}$ and $X_{\mathrm{j}}$ represent the independent variables $(i \neq \mathrm{j})$.

\subsection{Conventional Heat Reflux Extraction (HRE)}

A comparative study between the HRE and UAE was carried out to estimate the efficiency of the UAE process established in this work. The HRE of TF from P. cretica was performed under the optimized UAE conditions with slight modifications. In brief, $5.0 \mathrm{~g}$ of the pre-prepared sample was extracted three times under reflux with $170 \mathrm{~mL}$ of $57 \%$ ethanol at $75{ }^{\circ} \mathrm{C}$, each time for $2 \mathrm{~h}$. After the HRE, the extract was processed as the method described in Section 2.3.1.

\subsection{Measurement of Total Flavonoids Content (TFC)}

The total flavonoids content (TFC) was measured using the aluminium chloride colourimetric method reported by with slight modifications [25]. First, to $0.5 \mathrm{~mL}$ of the sample solution, $0.15 \mathrm{~mL}$ of $\mathrm{NaNO}_{2}(5 \%, w / v)$ was added. After the mixture was stirred for $5 \mathrm{~min}, 0.15 \mathrm{~mL}$ of $(10 \%, w / v) \mathrm{AlCl}_{3}$ was added. After another $5 \mathrm{~min}, 1 \mathrm{~mL}$ of $\mathrm{NaOH}(1 \mathrm{M})$ was added. The solution was then made up to a final volume of $5 \mathrm{~mL}$ by the addition of ultrapure water. After complete addition, the reaction mixture was further incubated at ambient temperature for $20 \mathrm{~min}$, and the absorbance was immediately recorded at $510 \mathrm{~nm}$ with an UV-vis Spectrophotometer (UV-2600, Shimadzu, Kyoto, Japan). Rutin was used as a reference, and the TFC was calculated according to the regression equation: $y=11.2736 x-0.0028$ 
$\left(R^{2}=0.9997\right.$, final rutin concentration $\left.18.12-72.48 \mu \mathrm{g} / \mathrm{mL}\right)$, where $y$ is the absorbance, $x$ is the content $(\mu \mathrm{g} / \mathrm{mL})$, and the TFY was calculated by the equation given below:

$$
\text { Extraction yield }(\%)=\frac{C \times V}{W} \times 100
$$

where $C$ represents the TFC $(\mathrm{mg} / \mathrm{mL}) ; V$ represents the total volume of extractive solution $(\mathrm{mL})$; and $W$ represents the dry weight of plant material $(\mathrm{mg})$.

\subsection{HPLC Analysis}

An HPLC system (Shimadzu Co., Kyoto, Japan) equipped with a multi-channel pump (LC-20AD) and a diode array detector (SPD-M20A) was used to analyze the extracts from P. cretica obtained by UAE under optimized conditions and HRE. A YMC-Pack ODS-A column $(5 \mu \mathrm{m}, 250 \mathrm{~mm} \times 4.6 \mathrm{~mm}$ id; YMC Co., Tokyo, Japan) was employed for all separations at $25^{\circ} \mathrm{C}$. The mobile phase was composed of $0.5 \%$ TFA in ultrapure water (solvent $A$ ) and methanol (solvent $B$ ). The elution procedure was as follows: 0-25 min, 25-45\% B; 25-40 min, 45-65\% B; 40-60 $\mathrm{min}, 65-90 \% \mathrm{~B} ; 60-65 \mathrm{~min}, 90-25 \% \mathrm{~B}$, with a flow rate of $0.5 \mathrm{~mL} / \mathrm{min}$. Detection was carried out at the wavelength of $254 \mathrm{~nm}$. The flavonoids in extracts from P. cretica were identified on the basis of comparison of the retention time and ultraviolet spectrum of standards, and the quantification of flavonoids was performed by the external standard method.

\subsection{Method Validation}

The method was validated for linearity, limit of detection (LOD), limit of quantification (LOQ), precision (inter-day and intra-day precision), stability, and accuracy following the International Conference on Harmonization (ICH) guideline and the previous reports [26,27].

Linearity was examined through the triplicate analysis of mixed standard solutions at six different concentrations, and the calibration curves were constructed by linear regression analysis of the integrated peak areas $(y)$ versus concentrations $(x)$. LOD and LOQ for each analyte under the HPLC conditions were determined at the signal-to-noise ratio $(\mathrm{S} / \mathrm{N})$ of 3 and 10 , respectively.

Intra-day and inter-day variations were chosen to evaluate the precision of the developed HPLC method. Intra-day precision was assessed by six injections of a mixed standard solution within a single day, and inter-day precision was validated with the mixed standard solution used above once a day for 3 consecutive days. The precision of this method was expressed as relative standard deviation (RSD). Stability was evaluated by analyzing the same sample at $0,2,4,6,8$, and $12 \mathrm{~h}$ at room temperature. The accuracy test was performed by the standard addition method. The authentic standards at three different concentration levels (low, medium, and large) were added to the sample, then extracted and quantified based on the established procedures. The recovery was counted according to the following formula:

$$
\text { Recovery }(\%)=\frac{\text { total detected amount }- \text { original amount }}{\text { added amount }} \times 100
$$

\subsection{Evaluation of Antioxidant Activity}

\subsubsection{Assay of DPPH• Radical Scavenging Activity}

The DPPH• radical scavenging capacity of total flavonoid extracts of $P$. cretica was investigated on the basis of the method reported by Shukla et al. [28] with a minor modification. Briefly, $0.8 \mathrm{~mL}$ of the DPPH solution $(0.1 \mathrm{mM}$ in ethanol) was mixed with $2.4 \mathrm{~mL}$ of total flavonoid extract solution at different concentrations $(25-250 \mu \mathrm{g} / \mathrm{mL}$ in ethanol). The reaction mixture was then shaken well and incubated at room temperature for $30 \mathrm{~min}$. The absorbance of the reaction mixture was recorded at $517 \mathrm{~nm}$. Ascrobic acid was used as a positive control in this work. The percentage of DPPH• radical scavenging was calculated using the following equation: 


$$
\text { Radical scavenging activity }(\%)=\frac{A_{0}-A_{1}}{A_{1}} \times 100
$$

where $A_{0}$ represents the absorbance of the reaction system without the extract and the $A_{1}$ represents the absorbance of the reaction system in the presence of the extract. The test was carried out in triplicate, and the $\mathrm{IC}_{50}$ was defined as the concentration of the extract that resulted in a $50 \%$ inhibition of DPPH• radical.

\subsubsection{Assay of $\mathrm{ABTS}^{+} \bullet$ Radical Scavenging Activity}

The method reported by Awe et al. [29] was adopted for the assay of $\mathrm{ABTS}^{+} \bullet$ radical scavenging activity. First, ABTS was dissolved in phosphate buffered saline (PBS, $0.01 \mathrm{M}, \mathrm{pH} 7.4$ ) to a $7 \mathrm{mM}$ concentration. The ABTS solution was then mixed with an equal volume of $\mathrm{K}_{2} \mathrm{~S}_{2} \mathrm{O}_{8}$ solution $(2.45 \mathrm{mM})$ in the dark at room temperature to produce $\mathrm{ABTS}^{+} \bullet$. After $16 \mathrm{~h}$, the $\mathrm{ABTS}^{+} \bullet$ solution was adjusted to a suitable absorbance $(0.70 \pm 0.02)$ using water at $734 \mathrm{~nm}$. To $2.0 \mathrm{~mL}$ of the prepared ABTS ${ }^{+} \bullet$ solution, $0.5 \mathrm{~mL}$ of various concentrations of extract solution $(25-150 \mu \mathrm{g} / \mathrm{mL})$ was added. The reaction mixture was then incubated in the dark at room temperature. A total of 10 mins later, the absorbance of the mixture was immediately recorded at $734 \mathrm{~nm}$. Trolox was used as a positive control in this experiment, and the percentage of $\mathrm{ABTS}^{+} \bullet$ radical scavenging was calculated using the Equation (4).

\subsubsection{Assay of NO• Radical Scavenging Activity}

The assay of NO• radical scavenging activity was carried out following the procedure of Shukla et al. [28] with a minor modification. Briefly, $5 \mathrm{mM}$ of SNP in PBS solution (0.01 M, pH 7.4) was prepared and mixed immediately with $2.0 \mathrm{~mL}$ of various concentrations of $P$. cretica extract $(25-250 \mu \mathrm{g} / \mathrm{mL})$. After $150 \mathrm{~min}$ of incubation at room temperature, $1.0 \mathrm{~mL}$ of Griess reagent ( $1 \%$ sulfanilamide in $2 \% \mathrm{H}_{3} \mathrm{PO}_{4}$ and $0.1 \%$ naphthylethylenediamine dihydrochloride) was added. The absorbance of the chromophore formed during the reaction was then recorded at $546 \mathrm{~nm}$. Ascrobic acid was used as a positive control in this work, and the percentage of $\mathrm{NO} \bullet$ radical scavenging was calculated using Equation (4).

\subsubsection{Assay of $\mathrm{Fe}^{2+}$ Chelating Activity}

The ferrous ion chelating activity of the extract was measured using the modified method reported by Tohma et al. [30]. In brief, this assay was carried out by mixing $1.0 \mathrm{~mL}$ of extract solution $(50-1600 \mu \mathrm{g} / \mathrm{mL})$ with $0.1 \mathrm{~mL}$ of $\mathrm{FeCl}_{2}$ solution $(2.0 \mathrm{mM}), 0.2 \mathrm{~mL}$ of ferrozine solution $(5.0 \mathrm{mM})$ and $2.7 \mathrm{~mL}$ of deionized water. After $10 \mathrm{~min}$ of incubation at room temperature, the absorbance of reaction mixture was recorded at $562 \mathrm{~nm}$, and EDTA-2Na was used as a positive control. The $\mathrm{Fe}^{2+}$ chelating activity was calculated according to Equation (4).

\subsection{Statistical Analysis}

All the experiments were performed in triplicate, and the results were shown as mean \pm standard deviation (SD). A variance analysis (ANOVA) is used and the comparison of the averages is carried out by the test of Duncan, and differences were regarded as significant when the $p<0.05$. The Design-Expert version 10 software (Stat-Ease Inc., Minneapolis, MN, USA) was employed for the RSM design and statistics analysis.

\section{Results}

\subsection{Single-Factor Experiments}

\subsubsection{Effect of Ethanol Concentration on the TFY}

In general, aqueous ethanol is an excellent solvent for the extraction of flavonoids from plants, and the selection of an appropriate ethanol concentration is a crucial step to improve extraction yield. 
In the present work, the impact of ethanol concentration on the TFY was studied first. As shown in Figure 1a, the TFY increased dramatically when the ethanol concentration varied from $30 \%$ to $60 \%$. However, the extraction yield exhibited a downward trend when the ethanol concentration was above $60 \%$, which was possibly due to the fact that higher ethanol concentration could more easily lead to dissolution of alcohol-soluble impurities [31]. Therefore, $60 \%$ ethanol was chosen as the best extraction solvent.

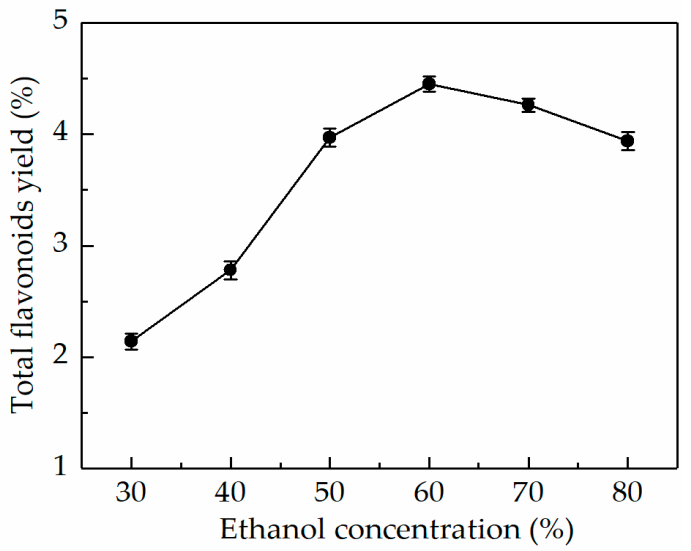

(a)

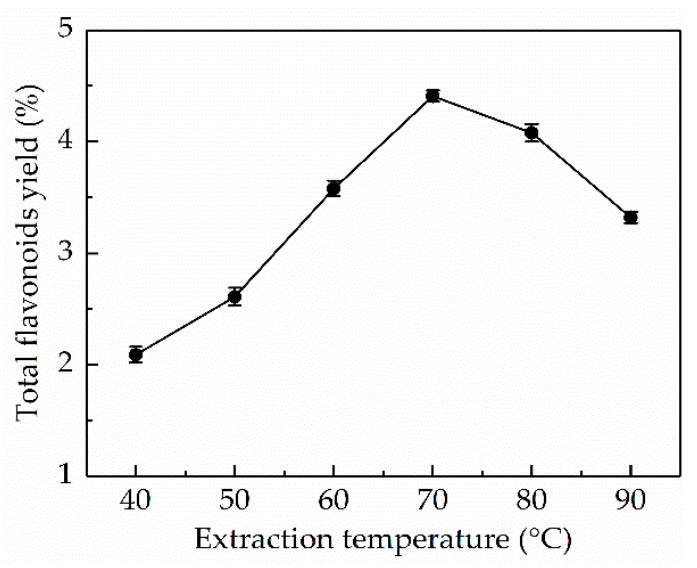

(c)

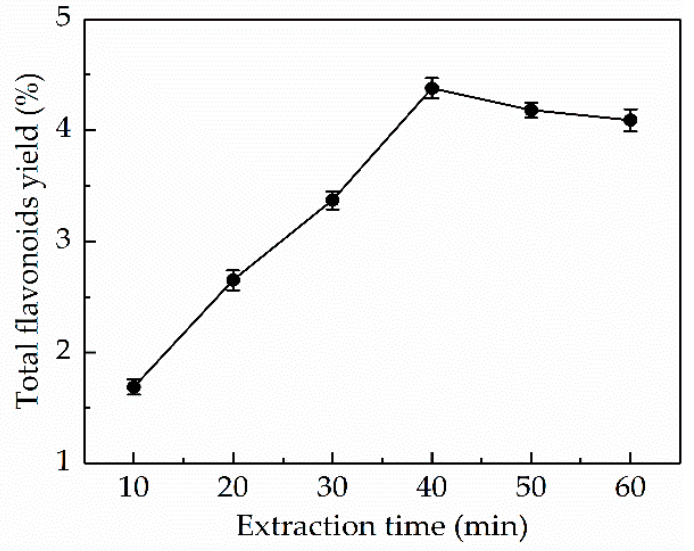

(b)

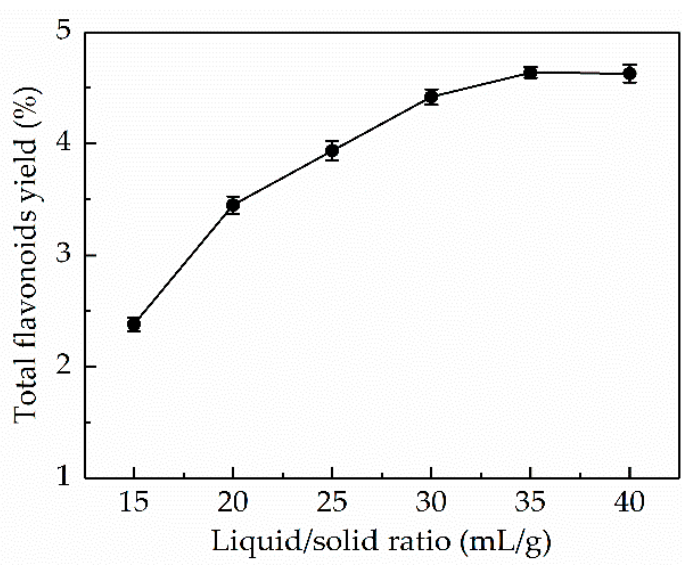

(d)

Figure 1. Effects of four independent variables on the total flavonoids yield (TFY): (a) Ethanol concentration; (b) extraction time; (c) extraction temperature; and (d) liquid/solid ratio.

\subsubsection{Effect of Extraction Time on the TFY}

In this work, the influence of extraction time (10-60 $\mathrm{min})$ on the TFY was researched. As shown in Figure $1 \mathrm{~b}$, the initial increase of extraction time (10-40 $\mathrm{min}$ ) resulted in an obvious improvement in the TFY. The extraction yield decreased slightly with the further increase in extraction time, which could be ascribed to the fact that longer extraction time will lead to an increase in the amount of dissolved impurities and the degradation of some flavonoids [32]. Thus, $40 \mathrm{~min}$ was regarded as the optimum extraction time.

\subsubsection{Effect of Extraction Temperature on the TFY}

There is no doubt that temperature is a significant factor influencing the extraction yield. Hence, in order to obtain the optimum extraction temperature, UAE processes were performed at 40, 50, $60,70,80$, and $90^{\circ} \mathrm{C}$, respectively, and the results were shown in Figure $1 \mathrm{c}$. There was a significant increase in the TFY (varying from $2.09 \pm 0.07 \%$ to $4.41 . \pm 0.05 \%$ ) with increasing extraction temperature from 40 to $60^{\circ} \mathrm{C}$. However, at higher extraction temperature (more than $60^{\circ} \mathrm{C}$ ), the TFY declined. 
One of the possible reasons for this was that the structure of the flavonoids was destroyed under high temperature [33]. Thus, $60^{\circ} \mathrm{C}$ was selected as the optimal extraction temperature.

\subsubsection{Effect of Liquid/Solid Ratio on the TFY}

The effect of liquid/solid ratio (15-40 mL/g) on the TFY was in Figure 1d. The TFY increased with the increasing liquid/solid ratio and reached a maximum $(4.64 \pm 0.05 \%)$ at $35 \mathrm{~mL} / \mathrm{g}$. Whereas, extraction yield reached a plateau phase when the liquid/solid ratio continued to rise above $35 \mathrm{~mL} / \mathrm{g}$. A high liquid/solid ratio would give rise to an increase in the cost of recovery. Hence, the optimal liquid/solid ratio was set at $35 \mathrm{~mL} / \mathrm{g}$.

\subsection{Optimization of UAE Process by RSM}

\subsubsection{Model Fitting and Statistical Analysis}

Due to the association between variables, BBD with four factors and three levels was employed to optimize the individual parameters. BBD matrix and response values were listed in Table 1. Subsequently, statistical regression analysis of experimental data was carried out, and a second-order polynomial equation yielded was represented as below:

$$
\begin{aligned}
Y= & 4.59-0.068 X_{1}+0.27 X_{2}+0.27 X_{3}+0.015 X_{4} \\
& -0.23 X_{1} X_{2}-0.29 X_{1} X_{3}+0.098 X_{1} X_{4}+0.14 X_{2} X_{3} \\
& -0.19 X_{2} X_{4}-0.098 X_{3} X_{4}-0.54 X_{1}^{2}-0.38 X_{2}{ }^{2} \\
& -0.55 X_{3}^{2}-0.33 X_{4}{ }^{2}
\end{aligned}
$$

where $X_{1}, X_{2}, X_{3}$, and $X_{4}$ are the ethanol concentration, extraction time, extraction temperature, and liquid/solid ratio, respectively. $Y$ is the predicted value of TFY.

Table 1. Box-Behnken design matrix and experimental values for the TFY.

\begin{tabular}{cccccc}
\hline Run & $\boldsymbol{X}_{\mathbf{1}}(\mathbf{\%})$ & $\boldsymbol{X}_{\mathbf{2}}(\mathbf{m i n})$ & $\boldsymbol{X}_{\mathbf{3}}\left({ }^{\circ} \mathbf{C}\right)$ & $\boldsymbol{X}_{\mathbf{4}}(\mathbf{m L} \mathbf{g})$ & $\boldsymbol{Y}(\mathbf{\%})$ \\
\hline 1 & $60(0)$ & $40(0)$ & $70(0)$ & $35(0)$ & 4.64 \\
2 & $70(1)$ & $30(-1)$ & $70(0)$ & $35(0)$ & 3.56 \\
3 & $60(0)$ & $30(-1)$ & $70(0)$ & $40(1)$ & 3.87 \\
4 & $60(0)$ & $30(-1)$ & $80(1)$ & $35(0)$ & 3.39 \\
5 & $60(0)$ & $40(0)$ & $80(1)$ & $30(-1)$ & 4.08 \\
6 & $50(-1)$ & $40(0)$ & $70(0)$ & $40(1)$ & 3.60 \\
7 & $50(-1)$ & $40(0)$ & $60(-1)$ & $35(0)$ & 2.95 \\
8 & $60(0)$ & $40(0)$ & $70(0)$ & $35(0)$ & 4.61 \\
9 & $50(-1)$ & $50(1)$ & $70(0)$ & $35(0)$ & 4.27 \\
10 & $50(-1)$ & $40(0)$ & $70(0)$ & $30(-1)$ & 3.97 \\
11 & $70(1)$ & $40(0)$ & $70(0)$ & $40(1)$ & 3.63 \\
12 & $60(0)$ & $40(0)$ & $80(1)$ & $40(1)$ & 4.04 \\
13 & $60(0)$ & $40(0)$ & $60(-1)$ & $40(1)$ & 3.58 \\
14 & $60(0)$ & $40(0)$ & $70(0)$ & $35(0)$ & 4.61 \\
15 & $60(0)$ & $50(1)$ & $80(1)$ & $35(0)$ & 4.23 \\
16 & $60(0)$ & $40(0)$ & $70(0)$ & $35(0)$ & 4.62 \\
17 & $60(0)$ & $40(0)$ & $60(-1)$ & $30(-1)$ & 3.23 \\
18 & $60(0)$ & $50(1)$ & $60(-1)$ & $35(0)$ & 3.61 \\
19 & $60(0)$ & $30(-1)$ & $70(0)$ & $30(-1)$ & 3.38 \\
20 & $70(1)$ & $40(0)$ & $60(-1)$ & $35(0)$ & 3.46 \\
21 & $60(0)$ & $50(1)$ & $70(0)$ & $40(1)$ & 4.01 \\
22 & $70(1)$ & $40(0)$ & $80(1)$ & $35(0)$ & 3.48 \\
23 & $60(0)$ & $40(0)$ & $70(0)$ & $35(0)$ & 4.48 \\
24 & $70(1)$ & $50(1)$ & $70(0)$ & $35(0)$ & 3.64 \\
25 & $50(-1)$ & $40(0)$ & $80(1)$ & $35(0)$ & 4.13 \\
\hline
\end{tabular}


Table 1. Cont.

\begin{tabular}{cccccc}
\hline Run & $\boldsymbol{X}_{\mathbf{1}} \mathbf{( \% )}$ & $\boldsymbol{X}_{\mathbf{2}}(\mathbf{m i n})$ & $\boldsymbol{X}_{\mathbf{3}}\left({ }^{\circ} \mathbf{C}\right)$ & $\boldsymbol{X}_{\mathbf{4}}(\mathbf{m L} / \mathbf{g})$ & $\boldsymbol{Y} \mathbf{( \% )}$ \\
\hline 26 & $60(0)$ & $50(1)$ & $70(0)$ & $30(-1)$ & 4.28 \\
27 & $70(1)$ & $40(0)$ & $70(0)$ & $30(-1)$ & 3.61 \\
28 & $50(-1)$ & $30(-1)$ & $70(0)$ & $35(0)$ & 3.27 \\
29 & $60(0)$ & $30(-1)$ & $60(-1)$ & $35(0)$ & 3.33 \\
\hline
\end{tabular}

The fitness and adequacy of the regression model were evaluated using a variance analysis (ANOVA), and results were given in Table 2. F-value (41.92) and $p$-value $(<0.0001)$ of the regression model indicated that the established model was very significant. Whereas, $F$-value (3.28) and $p$-value (0.1317) of the lack of fit indicated that the lack of fit was not significant as compared with the pure error. In addition, the determination coefficient $\left(R^{2}\right)$ obtained for this model was 0.9767 , implying that the model could satisfactorily fit the variability of the TFY. The predicted $R^{2}$ of 0.8764 was in reasonable agreement with the adjusted $R^{2}$ of 0.9534 , implying that the predicted values were highly consistent with the experimental values. In this study, the linear coefficients $\left(X_{1}, X_{2}\right.$, and $\left.X_{3}\right)$, quadratic term coefficients $\left(X_{12}, X_{22}, X_{32}\right.$, and $\left.X_{42}\right)$, and the cross product coefficients $\left(X_{1} X_{2}, X_{1} X_{3}, X_{2} X_{3}\right.$, and $\left.X_{2} X_{4}\right)$ had statistically significant effects on the TFY $(p<0.05)$.

Table 2. The analysis of variance for the second-order polynomial model.

\begin{tabular}{cccccc}
\hline Source & Sum of Squares & Df & Mean Square & F-Value & $p$-Value \\
\hline Model & 6.28 & 14 & 0.45 & 41.92 & $<0.0001$ \\
$X_{1}$ & 0.055 & 1 & 0.055 & 5.11 & 0.0403 \\
$X_{2}$ & 0.87 & 1 & 0.87 & 81.73 & $<0.0001$ \\
$X_{3}$ & 0.85 & 1 & 0.85 & 79.22 & $<0.0001$ \\
$X_{4}$ & 0.0027 & 1 & 0.0027 & 0.25 & 0.6233 \\
$X_{1} X_{2}$ & 0.21 & 1 & 0.21 & 19.77 & 0.0006 \\
$X_{1} X_{3}$ & 0.34 & 1 & 0.34 & 31.43 & $<0.0001$ \\
$X_{1} X_{4}$ & 0.038 & 1 & 0.038 & 3.55 & 0.0804 \\
$X_{2} X_{3}$ & 0.078 & 1 & 0.078 & 7.32 & 0.0170 \\
$X_{2} X_{4}$ & 0.14 & 1 & 0.14 & 13.49 & 0.0025 \\
$X_{3} X_{4}$ & 0.038 & 1 & 0.038 & 3.55 & 0.0804 \\
$X_{12}$ & 1.90 & 1 & 1.90 & 177.64 & $<0.0001$ \\
$X_{22}$ & 0.95 & 1 & 0.95 & 88.74 & $<0.0001$ \\
$X_{32}$ & 1.95 & 1 & 1.95 & 182.59 & $<0.0001$ \\
$X_{42}$ & 0.70 & 1 & 0.70 & 65.06 & $<0.0001$ \\
Residual & 0.15 & 14 & 0.011 & & \\
Lack of fit & 0.13 & 10 & 0.013 & 3.28 & 0.1317 \\
Pure error & 0.016 & 4 & 0.004 & & \\
Cor total & 6.43 & 28 & & & \\
$R^{2}$ & 0.9767 & & & & \\
Adjusted $R^{2}$ & 0.9534 & & & & \\
\hline
\end{tabular}

\subsubsection{Response Surface Analysis}

The three-dimensional (3D) response surface images illustrate the mutual influence of any two independent variables on the dependent variable while keeping other variables at the 0 level, and the shape of the 3D response surface plots provides information on the influence degree. To be specific, elliptical or saddle shapes of the 3D surfaces usually represent the interaction between two independent variables on the dependent variable, which is relatively significant, whereas a gently sloping surface indicates that the interaction between two factors on the dependent variable is relatively mild $[34,35]$.

Figure 2a-f offered a visual interpretation of the interactions between two variables $\left(X_{1} X_{2}, X_{1} X_{3}\right.$, $X_{1} X_{4}, X_{2} X_{3}, X_{2} X_{4}$, and $\left.X_{3} X_{4}\right)$ on the response variable $(Y)$. Figure $2 \mathrm{a}-\mathrm{c}$ showed the influences of ethanol concentration $\left(X_{1}\right)$ with extraction time $\left(X_{2}\right)$ and extraction temperature $\left(X_{3}\right)$ on the extraction yields of TF, respectively. The initial increase of $X_{1}(50 \%$ to about $57 \%)$ led to an increase in TFY and followed by a decline thereafter (about $57 \%$ to $70 \%$ ). Similarly, as could be seen from Figure $2 \mathrm{a}, \mathrm{d}, \mathrm{e}$, a rapid rise in TFY was obtained when $X_{2}$ varied from 30 to about $46 \mathrm{~min}$, then the extraction yield of TF was decreased slowly with increasing extraction time. Figure $2 b, d, f$ indicated that with an increase of $X_{3}$ from 60 to about $74^{\circ} \mathrm{C}$, the TFY increased quickly, followed by a slight decline with further 
increase in $X_{3}$. According to Figure 2c,e,f, it could be found that a maximum level of TFY was obtained at a $X_{4}$ of $34 \mathrm{~mL} / \mathrm{g}$. The graphs also indicated that the influence of $X_{4}$ on the TFY is insignificant $(p>0.05)$. In addition, as evident from Figure $2 c$, the interaction effect of $X_{1}$ and $X_{4}$ had a insignificant influence on the TFY from P. cretica $(p>0.05)$.

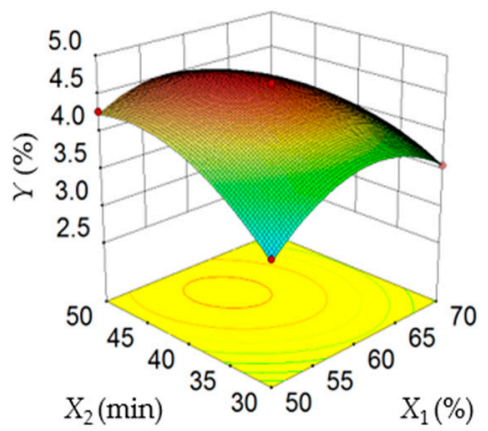

(a)

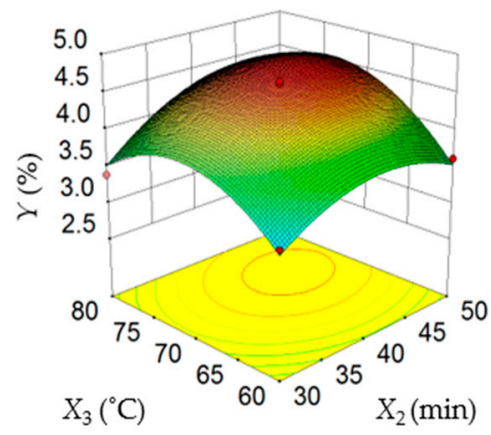

(d)

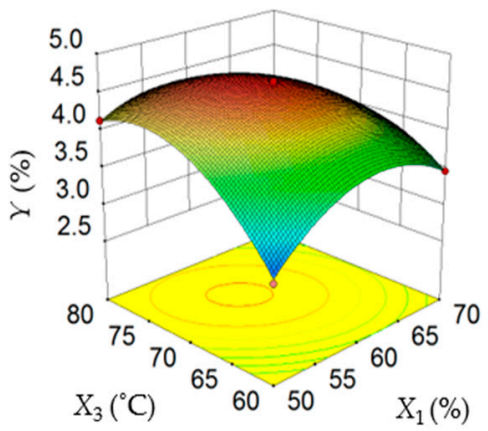

(b)

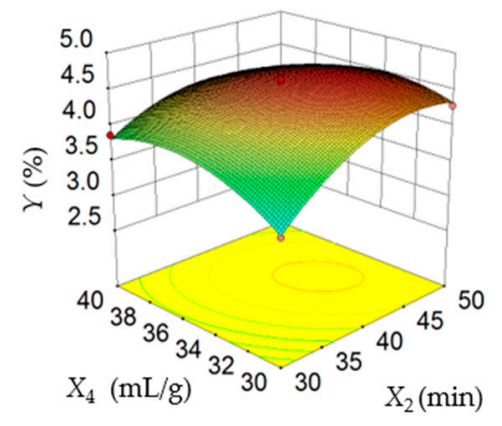

(e)

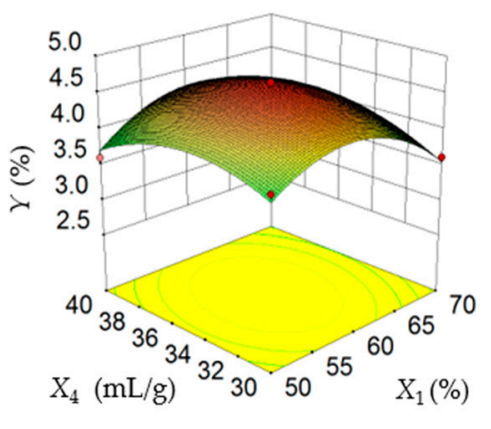

(c)

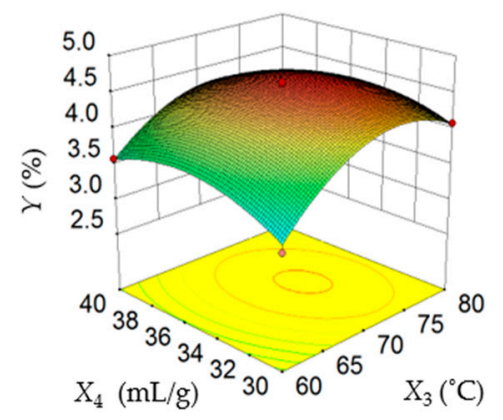

(f)

Figure 2. Response surface plots showing interaction between different variables $\left(X_{1}\right.$ : Ethanol concentration; $X_{2}$ : Extraction time; $X_{3}$ : Extraction temperature; and $X_{4}$ : Liquid/solid ratio) on the TFY.

\subsubsection{Validation of the Optimized Model}

The optimal conditions for UAE of TF from $P$. cretica obtained by RSM were as follows: Ethanol concentration $\left(X_{1}\right) 56.74 \%$, extraction time $\left(X_{2}\right) 45.94 \mathrm{~min}$, extraction temperature $\left(X_{3}\right) 74.27{ }^{\circ} \mathrm{C}$, and liquid/solid ratio $\left(X_{4}\right) 33.69 \mathrm{~mL} / \mathrm{g}$. Under optimized UAE conditions, the theoretical TFY was $4.74 \%$. Subsequently, in order to prove the reliability of the prediction model, the confirmatory experiments were carried out under the optimized extraction conditions. Confirmatory experiments gave a satisfactory result that the TFY was $4.71 \pm 0.04 \%$, which was well-matched with theoretical value. Therefore, it could be concluded that the regression model was appropriate for the optimization of the UAE process of TF from $P$. cretica.

In this study, HRE was also performed to confirm the superiority of UAE of TF from P. cretica. The results demonstrated that the TFY obtained by UAE under optimized conditions was higher than that obtained by HRE (3.48 $\pm 0.05 \%)$. Additionally, a lot of previous literatures have reported that UAE gave a higher TFY obtained by UAE when compared with HRE. This phenomenon was believed to be caused by cavitation, vibration, crushing, mixing, and other comprehensive effects produced by ultrasound, which enhanced the extractability of flavonoids [36].

\subsection{Method Validation for Quantitative Analysis of Five Flavonoids}

Table 3 listed the linear equation, correlation coefficient $\left(R^{2}\right)$, linear range, LOD, and LOQ of each compound determined. It could be found that all calibration curves showed good linearity 
$\left(R^{2} \geq 0.9995\right)$ within the tested concentration range. For these compounds, the LOD values ranged from 0.014 to $0.094 \mu \mathrm{g} / \mathrm{mL}$, while the LOQ values ranged from 0.16 to $1.31 \mu \mathrm{g} / \mathrm{mL}$. The results of precision, stability, and accuracy tests were shown in Table 4. All RSD values of the intra-day and inter-day precision ranged from $0.94-2.43 \%$ and $1.87-2.51 \%$, respectively, which indicated good precision of the developed method. The results of the stability test showed that the RSD values of peak areas of the five compounds were $\leq 2.56 \%$, which indicated that the sample was stable for $12 \mathrm{~h}$ at room temperature. According to the calculation, the mean recoveries of five compounds ranged from 98.93 to $101.3 \%$, with RSD values ranging from 0.85 to $2.19 \%$, which demonstrated a good accuracy of the developed method. In sum, the verification tests demonstrated that the developed method was feasible for the simultaneous quantification of five compounds from P. cretica.

Table 3. Linear regression, limit of detection (LOD), and limit of quantification (LOQ) of the five tested compounds.

\begin{tabular}{cccccc}
\hline Analytes & Linear Equation & $\boldsymbol{R}^{\mathbf{2}}$ & Linear Range $(\mu \mathrm{g} / \mathrm{mL})$ & LOD $(\mu \mathrm{g} / \mathrm{mL})$ & LOQ $(\mu \mathrm{g} / \mathrm{mL})$ \\
\hline luteolin-7-O-glucoside & $y=73104 x-11077$ & 0.9995 & $5.00-100$ & 0.051 & 0.67 \\
Rutin & $y=62441 x+21414$ & 0.9998 & $5.00-100$ & 0.094 & 0.042 \\
Quercitrin & $y=135884 x+32168$ & 0.9997 & $2.50-100$ & 0.014 & 0.44 \\
Luteolin & $y=146356 x-48920$ & 0.9998 & $1.00-100$ & 0.026 & 0.34 \\
Apigenin & $y=86719 x-22486$ & 0.9999 & $1.00-100$ & & 0.16 \\
\hline
\end{tabular}

Table 4. Precision, stability, and recovery of the five tested compounds.

\begin{tabular}{|c|c|c|c|c|c|}
\hline \multirow{2}{*}{ Analytes } & \multicolumn{2}{|c|}{ Precision (RSD, \%) } & \multirow{2}{*}{$\begin{array}{l}\text { Stability } \\
\text { (RSD, \%) }\end{array}$} & \multicolumn{2}{|l|}{ Recovery } \\
\hline & Intra-Day & Inter-Day & & Mean Recovery (\%) & RSD ( $\%)$ \\
\hline Luteolin-7-O-glucoside & 1.34 & 2.51 & 2.56 & 99.67 & 0.85 \\
\hline Rutin & 2.11 & 1.87 & 2.48 & 100.4 & 1.48 \\
\hline Quercitrin & 0.94 & 2.02 & 1.89 & 101.3 & 2.19 \\
\hline Luteolin & 1.52 & 1.98 & 2.05 & 98.93 & 1.83 \\
\hline Apigenin & 2.43 & 2.16 & 2.33 & 99.21 & 2.07 \\
\hline
\end{tabular}

\subsection{Analysis of Flavonoids in the Extracts by HPLC}

Without any doubt, pharmacological activity of P. cretica depends on its chemical constituents. Therefore, flavonoid profiles in the P. cretica extracts were analyzed by HPLC. Figure 3 indicated that the HPLC chromatograms of extracts obtained by UAE and HRE showed highly similar characteristics. A total of five flavonoids, including luteolin-7-O-glucoside, rutin, quercetin, luteolin, and apigenin, were identified, and their elution times were 37.340,39.021, 43.031, 50.568, and 54.306 min, respectively. Based on the results of HPLC quantitative analysis, the contents of the five flavonoids (mg/g plant material, dry weight) were in the following descending order: Luteolin-7-O-glucoside $(3.237 \pm 0.015 \mathrm{mg} / \mathrm{g})>$ rutin $(1.483 \pm 0.009 \mathrm{mg} / \mathrm{g})>$ apigenin $(0.803 \pm 0.013 \mathrm{mg} / \mathrm{g})>$ luteolin $(0.679 \pm 0.007 \mathrm{mg} / \mathrm{g})>$ quercitrin $(0.582 \pm 0.011 \mathrm{mg} / \mathrm{g})$. However, the contents of five flavonoids extracted by HRE were all lower compared to the UAE: Luteolin-7-O-glucoside $(2.862 \pm 0.005 \mathrm{mg} / \mathrm{g})>$ rutin $(1.133 \pm 0.007 \mathrm{mg} / \mathrm{g})>$ apigenin $(0.659 \pm 0.011 \mathrm{mg} / \mathrm{g})>$ luteolin $(0.486 \pm 0.009 \mathrm{mg} / \mathrm{g})>$ quercitrin $(0.574 \pm 0.013 \mathrm{mg} / \mathrm{g})$. Thus, it could be concluded that the UAE was a promising extraction method for the separation of bioactive flavonoids from P. cretica in the future. To our knowledge, this work was the first quantitative analysis of these five flavonoids in P. cretica. 


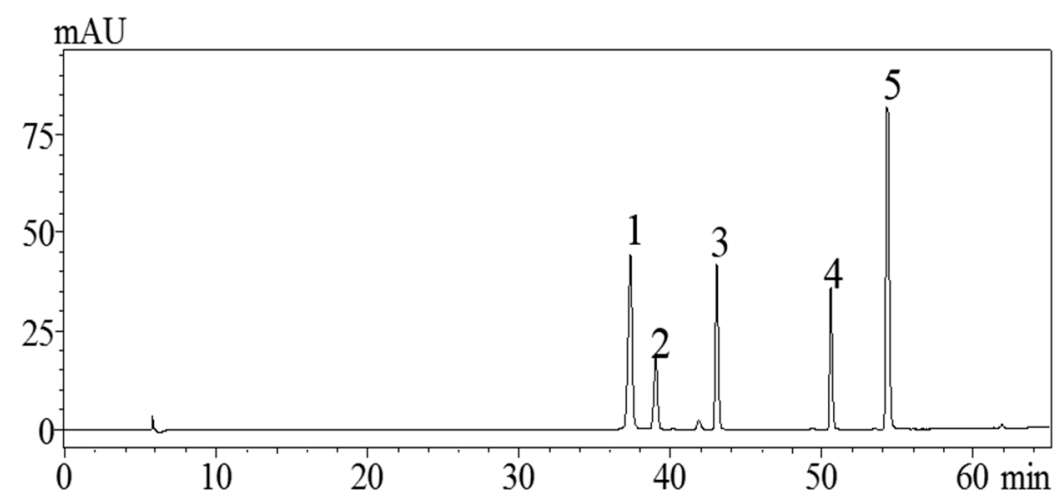

(a)

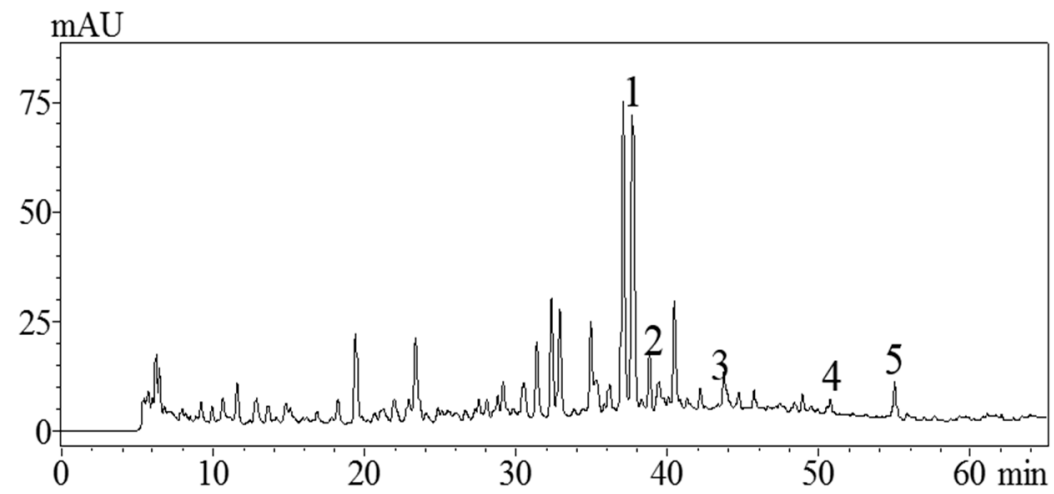

(b)

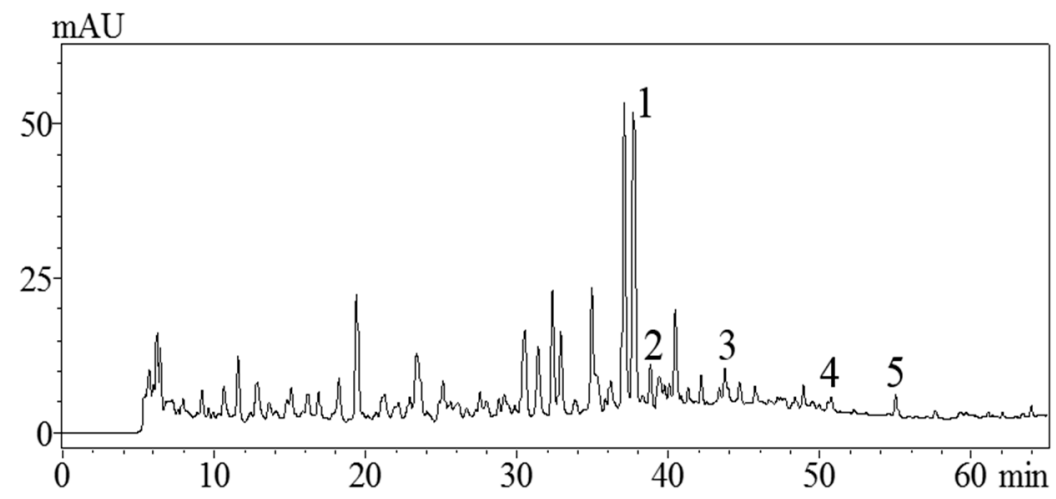

(c)

Figure 3. HPLC profiles of standards mixture (a) and P. cretica extract obtained by optimized ultrasonic-assisted extraction (UAE) (b). P. cretica extract obtained by heat reflux extraction (HRE) (c). Peaks (1): Luteolin-7-O-glucoside, (2) rutin, (3) quercitrin, (4) luteolin, and (5) apigenin.

\subsection{Antioxidant Activity}

\subsubsection{DPPH• Radical Scavenging Activity}

The DPPH• radical scavenging activity assay is a fairly common method to evaluate the antioxidant activity of natural products [37]. A comparison of the ascorbic acid and the P. cretica extract obtained by optimized UAE was performed, and the results are shown in Figure 4. It was observed that the $\mathrm{DPPH} \bullet$ radical scavenging effect of the P. cretica extract was increased with increasing concentration. 
The P. cretica extract at the test concentrations of $25,50,100,150,200$, and $250 \mu \mathrm{g} / \mathrm{mL}$ showed $21.23 \pm 2.78$, $40.45 \pm 3.04,56.17 \pm 2.45,65.56 \pm 3.14,77.13 \pm 2.98$, and $85.94 \pm 2.37 \%$ DPPH• radical scavenging, respectively. The $\mathrm{IC}_{50}$ value of the $P$. cretica extract was $74.49 \mu \mathrm{g} / \mathrm{mL}$, while for ascorbic acid it was $35.19 \mu \mathrm{g} / \mathrm{mL}$. The results indicated that the UAE extract of P. cretica had a good potential for scavenging $\mathrm{DPPH} \bullet$ radical. It has been reported that DPPH• radical scavenging activity of plant extracts is ascribable to the presence of flavonoids [38].

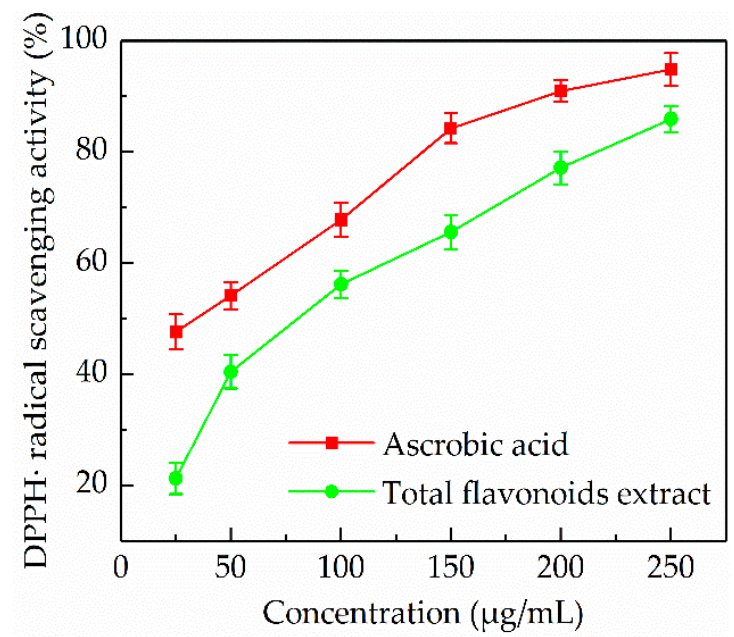

Figure 4. Scavenging activity of $P$. cretica extract obtained by optimized ultrasound-assisted extraction against DPPH• radical compared with ascorbic acid.

\subsection{2. $\mathrm{ABTS}^{+} \bullet$ Radical Scavenging Activity}

One of the most widely used organic radicals for the determination of antioxidant activity of natural products is the radical cation derived ABTS [39]. The results of $\mathrm{ABTS}^{+} \bullet$ radical scavenging activity of the P. cretica extract at different concentrations $(25-150 \mu \mathrm{g} / \mathrm{mL})$ were shown in Figure 5 . It was found that the $P$. cretica extract had a scavenging activity on the ABTS ${ }^{+} \bullet$ radical in a dose dependent manner. The $\mathrm{IC}_{50}$ value of standard trolox was $30.10 \mu \mathrm{g} / \mathrm{mL}$, while the $\mathrm{IC}_{50}$ value of the $P$. cretica extract was $82.92 \mu \mathrm{g} / \mathrm{mL}$. A $150 \mu \mathrm{g} / \mathrm{mL}$ of the P. cretica extract exhibited $78.41 \pm 2.97 \%$ inhibition. From these results, it could be stated that the P. cretica extract was a good $\mathrm{ABTS}^{+} \bullet$ radical scavenger.

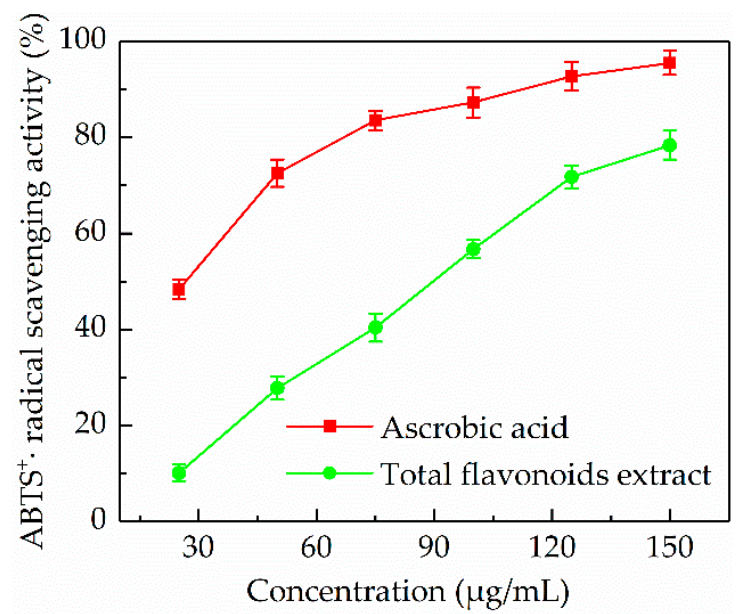

Figure 5. Scavenging activity of the P. cretica extract obtained by optimized ultrasound-assisted extraction against $\mathrm{ABTS}^{+} \bullet$ radical compared with trolox. 


\subsubsection{NO• Radical Scavenging Activity}

Despite the potential health benefits of NO• radical, its role in causing oxidative damage is becoming progressively prominent [40]. In this work, the scavenging effect of the P. cretica extract on NO• radical was studied. Figure 6 showed that the P. cretica extract within the concentration range tested $(25-250 \mu \mathrm{g} / \mathrm{mL})$ exhibited $\mathrm{NO} \bullet$ radical scavenging activity in a dose-dependent manner. Especially, the $P$. cretica extract exhibited a maximum percentage scavenging of $82.71 \pm 1.54 \%$, which was comparable to the $\mathrm{NO} \bullet$ radical scavenging activity of ascorbic acid. The $\mathrm{IC}_{50}$ value of ascorbic acid was $51.60 \mu \mathrm{g} / \mathrm{mL}$, and for the P. cretica extract it was $89.12 \mu \mathrm{g} / \mathrm{mL}$. Results indicated that P. cretica might serve as an excellent NO• radical scavenger due to the high level of flavonoids. It has been reported that the flavonoids are very powerful NO• radical scavengers [41].

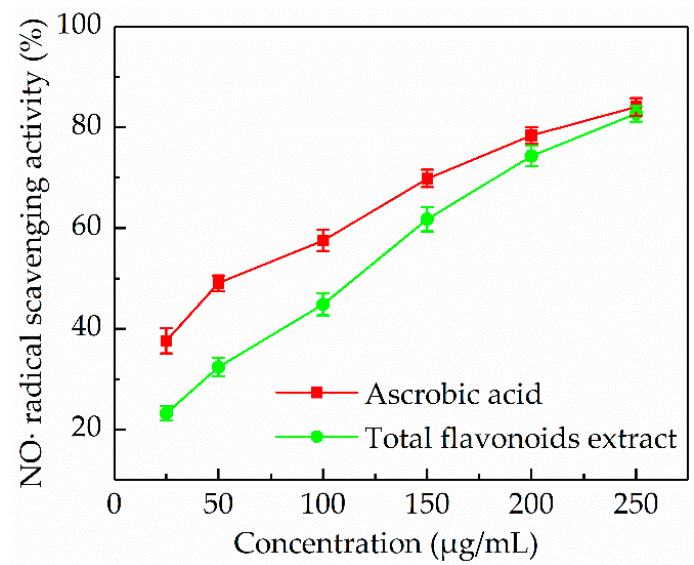

Figure 6. NO• radical scavenging activity of the $P$. cretica extract obtained by optimized ultrasound-assisted compared with ascorbic acid.

\subsection{4. $\mathrm{Fe}^{2+}$ Chelating Activity}

It has been reported that $\mathrm{Fe}^{2+}$ is a powerful pro-oxidant among various metal ions and $\mathrm{Fe}^{2+}$ chelation may prevent oxidative damage through retarding metal-catalyzed oxidation and inhibiting ROS production [42]. In this work, the $\mathrm{Fe}^{2+}$ chelating activity of the P. cretica extract was determined and compared with a chelating standard (EDTA-2Na). As shown in Figure 7, at different test doses of $50,100,200,400,800$, and $1600 \mu \mathrm{g} / \mathrm{mL}$, the $\mathrm{Fe}^{2+}$ chelating activity of the P. cretica extract was $4.74 \pm 1.77$, $9.98 \pm 1.89,18.65 \pm 1.86,31.56 \pm 2.48,51.87 \pm 2.17$, and $74.21 \pm 1.83 \%$, respectively, with an IC $_{50}$ value of $713.41 \mu \mathrm{g} / \mathrm{mL}$. According to these results, it could be concluded that the P. cretica extract had certain $\mathrm{Fe}^{2+}$ chelating activity.

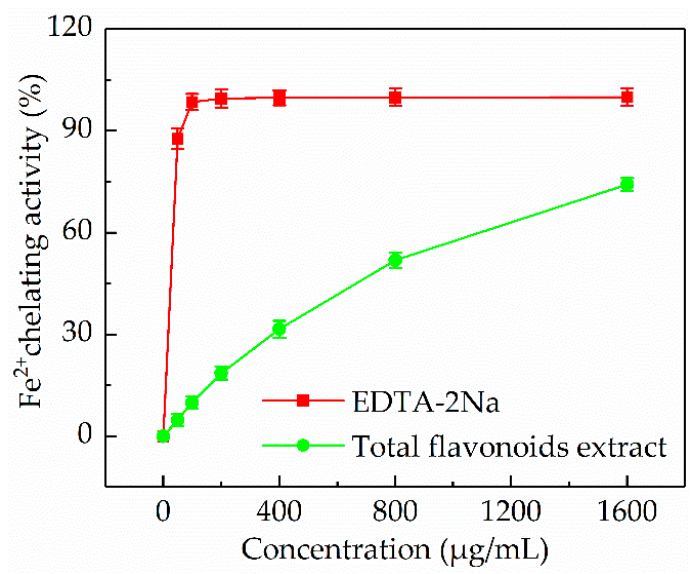

Figure 7. $\mathrm{Fe}^{2+}$ chelating activity of the P. cretica extract obtained by optimized ultrasound-assisted compared with EDTA-2Na. 


\section{Conclusions}

In this work, the UAE was proved to be a sample, rapid, and effective procedure for the extraction of TF from P. cretica, and the process parameters optimized by RSM were as follows: Ethanol concentration $56.74 \%$, extraction time $45.94 \mathrm{~min}$, extraction temperature $74.27{ }^{\circ} \mathrm{C}$, and liquid/solid ratio $33.69 \mathrm{~mL} / \mathrm{g}$. Under optimized UAE conditions, the TFY was $4.71 \pm 0.04 \%$, which was higher than that obtained by HRE. Moreover, HPLC analysis indicated that luteolin-7-O-glucoside, rutin, quercitrin, luteolin, and apigenin were the predominant flavonoids in P. cretica. It was also found that UAE is more suitable than HRE for the extraction of these compounds. In addition, the P. cretica extract obtained through the

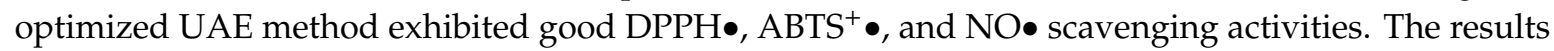
of the present wok should contribute to the further and deeper investigation of $P$. cretica, which might be used as a novel source of natural antioxidants.

Author Contributions: Conceptualization, W.H.; methodology, W.H. and M.H.; software, A.W., K.H., and X.S.; validation, W.H. and Z.X; formal analysis, D.C.; investigation, M.H. and R.L.; resources, W.H.; data curation, M.H. and J.S.; writing—original draft preparation, M.H.; writing—review and editing, W.H.; supervision, Y.S.; project administration, W.H.; funding acquisition, W.H.

Funding: This research was funded by the "Thirteenth Five-Year Plan" for the National Key Research and Development Program (No. 2016YFD0400903) and National Natural Science Foundation of China (No. 31471923).

Conflicts of Interest: The authors declare no conflict of interest.

\section{References}

1. Chao, Y.S.; Rouhan, G.; Amoroso, V.B.; Chiou, W.L. Molecular phylogeny and biogeography of the fern genus Pteris (Pteridaceae). Ann. Bot. 2014, 114, 109-124. [CrossRef] [PubMed]

2. Testo, W.L.; Watkins, J.E.; Pittermann, J.; Momin, R. Pteris $\times$ caridadiae (Pteridaceae), a new hybrid fern from Costa Rica. Brittonia 2015, 67, 138-143. [CrossRef]

3. Harinantenaina, L.; Matsunami, K.; Otsuka, H. Chemical constituents of Pteris cretica Linn. (Pteridaceae). Biochem. Syst. Ecol. 2009, 37, 133-137. [CrossRef]

4. Qiu, M.; Yang, B.; Cao, D.; Zhu, J.; Jin, J.; Chen, Y.; Zhou, L.; Luo, X.; Zhao, Z. Two new hydroxylated ent-kauranoic acids from Pteris semipinnata. Phytochem. Lett. 2016, 16, 156-162. [CrossRef]

5. Harinantenaina, L.; Matsunami, K.; Otsuka, H. Chemical and biologically active constituents of Pteris multifida. J. Nat. Med. 2008, 62, 452-455. [CrossRef] [PubMed]

6. Wang, H.B.; Wong, M.H.; Lan, C.Y.; Qin, Y.R.; Shu, W.S.; Qiu, R.L.; Ye, Z.H. Effect of arsenic on flavonoid contents in Pteris species. Biochem. Syst. Ecol. 2010, 38, 529-537. [CrossRef]

7. Imperato, F.; Nazzaro, R. Luteolin 7-O-sophoroside from Pteris cretica. Phytochemistry 1996, 41, $337-338$. [CrossRef]

8. Luo, X.; Li, C.; Luo, P.; Lin, X.; Ma, H.; Seeram, N.P.; Song, C.; Xu, J.; Gu, Q. Pterosin sesquiterpenoids from Pteris cretica as hypolipidemic agents via activating liver $X$ receptors. J. Nat. Prod. 2016, 79, 3014-3021. [CrossRef]

9. Ge, X.; Ye, G.; Li, P.; Tang, W.J.; Gao, J.L.; Zhao, W.M. Cytotoxic diterpenoids and sesquiterpenoids from Pteris multifida. J. Nat. Prod. 2008, 71, 227-231. [CrossRef]

10. Shi, Y.S.; Zhang, Y.; Hu, W.Z.; Zhang, X.F.; Fu, X.; Lv, X. Dihydrochalcones and diterpenoids from Pteris ensiformis and their bioactivities. Molecules 2017, 22, 1413. [CrossRef]

11. Kim, J.W.; Seo, J.Y.; Oh, W.K.; Sung, S.H. Anti-neuroinflammatory ent-kaurane diterpenoids from Pteris multifida roots. Molecules 2017, 22, 27. [CrossRef] [PubMed]

12. Singh, M.; Govindarajan, R.; Rawat, A.K.S.; Khare, P.B. Antimicrobial flavonoid rutin from Pteris vittata L. against pathogenic gastrointestinal microflora. Am. Fern J. 2008, 98, 98-104. [CrossRef]

13. Chen, Y.H.; Chang, F.R.; Lin, Y.J.; Wang, L.; Chen, J.F.; Wu, Y.C.; Wu, M.J. Identification of phenolic antioxidants from Sword Brake fern (Pteris ensiformis Burm.). Food Chem. 2007, 105, 48-56. [CrossRef]

14. Dai, G.C.; Hu, B.; Zhang, W.F.; Peng, F.; Wang, R.; Liu, Z.Y.; Xue, B.X.; Liu, J.Y.; Shan, Y.X. Chemical characterization, anti-benign prostatic hyperplasia effect and subchronic toxicity study of total flavonoid extract of Pteris multifida. Food Chem. Toxicol. 2017, 108, 524-531. [CrossRef] [PubMed] 
15. Yang, R.F.; Geng, L.L.; Lu, H.Q.; Fan, X.D. Ultrasound-synergized electrostatic field extraction of total flavonoids from Hemerocallis citrina baroni. Ultrason. Sonochem. 2017, 34, 571-579. [CrossRef] [PubMed]

16. Delgado-Povedano, M.M.; de Castro, M.D.L. A review on enzyme and ultrasound: A controversial but fruitful relationship. Anal. Chim. Acta 2015, 889, 1-21. [CrossRef] [PubMed]

17. Wen, C.; Zhang, J.; Zhang, H.; Dzah, C.S.; Zandile, M.; Duan, Y.; Ma, H.; Luo, X. Advances in ultrasound assisted extraction of bioactive compounds from cash crops-A review. Ultrason. Sonochem. 2018, 48, 538-549. [CrossRef]

18. Jing, C.L.; Dong, X.F.; Tong, J.M. Optimization of ultrasonic-assisted extraction of flavonoid compounds and antioxidants from alfalfa using response surface method. Molecules 2015, 20, 15550-15571. [CrossRef]

19. Zhang, H.; Xie, G.; Tian, M.; Pu, Q.; Qin, M. Optimization of the ultrasonic-assisted extraction of bioactive flavonoids from Ampelopsis grossedentata and subsequent separation and purification of two flavonoid aglycones by high-speed counter-current chromatography. Molecules 2016, 21, 1096. [CrossRef]

20. Wang, B.; Qu, J.; Luo, S.; Feng, S.; Li, T.; Yuan, M.; Huang, Y.; Liao, J.; Yang, R.; Ding, C. Optimization of ultrasound-assisted extraction of flavonoids from olive (Olea europaea) leaves, and evaluation of their antioxidant and anticancer activities. Molecules 2018, 23, 2513. [CrossRef]

21. Majd, M.H.; Rajaei, A.; Bashi, D.S.; Mortazavi, S.A.; Bolourian, S. Optimization of ultrasonic-assisted extraction of phenolic compounds from bovine pennyroyal (Phlomidoschema parviflorum) leaves using response surface methodology. Ind. Crop. Prod. 2014, 57, 195-202. [CrossRef]

22. Balavigneswaran, C.K.; Kumar, T.S.J.; Packiaraj, R.M.; Veeraraj, A.; Prakash, S. Anti-oxidant activity of polysaccharides extracted from Isocrysis galbana using RSM optimized conditions. Int. J. Biol. Macromol. 2013, 60, 100-108. [CrossRef] [PubMed]

23. Sun, Y.; Li, T.; Yan, J.; Liu, J. Technology optimization for polysaccharides (POP) extraction from the fruiting bodies of Pleurotus ostreatus by Box-Behnken statistical design. Carbohydr. Polym. 2010, 80, 242-247. [CrossRef]

24. Wang, W.; Li, Q.; Liu, Y.; Chen, B. Ionic liquid-aqueous solution ultrasonic-assisted extraction of three kinds of alkaloids from Phellodendron amurense Rupr and optimize conditions use response surface. Ultrason. Sonochem. 2015, 24, 13-18. [CrossRef] [PubMed]

25. Choi, J.; An, X.; Lee, B.H.; Lee, J.S.; Heo, H.J.; Kim, T.; Ahn, J.W.; Kim, D.O. Protective effects of bioactive phenolics from jujube (Ziziphus jujuba) seeds against $\mathrm{H}_{2} \mathrm{O}_{2}$-induced oxidative stress in neuronal PC-12 cells. Food Sci. Biotechnol. 2015, 24, 2219-2227. [CrossRef]

26. Bae, I.K.; Ham, H.M.; Jeong, M.H.; Kim, D.H.; Kim, H.J. Simultaneous determination of 15 phenolic compounds and caffeine in teas and mate using RP-HPLC/UV detection: Method development and optimization of extraction process. Food Chem. 2015, 172, 469-475. [CrossRef]

27. Zhou, F.; Zhang, L.; Gu, L.; Zhang, Y.; Hou, C.; Bi, K.; Chen, X.; Zhang, H. Simultaneous quantification of 13 compounds in Guanxin Shutong Capsule by HPLC method. J. Chromatogr. Sci. 2016, 54, 971-976. [CrossRef]

28. Shukla, S.; Mehta, A.; Bajpai, V.K.; Shukla, S. In vitro antioxidant activity and total phenolic content of ethanolic leaf extract of Stevia rebaudiana Bert. Food Chem. Toxicol. 2009, 47, 2338-2343. [CrossRef]

29. Awe, F.B.; Fagbemi, T.N.; Ifesan, B.O.T.; Badejo, A.A. Antioxidant properties of cold and hot water extracts of cocoa, Hibiscus flower extract, and ginger beverage blends. Food Res. Int. 2013, 52, 490-495. [CrossRef]

30. Tohma, H.S.; Gulçin, I. Antioxidant and radical scavenging activity of aerial parts and roots of Turkish liquorice (Glycyrrhiza glabra L.). Int. J. Food Prop. 2010, 13, 657-671. [CrossRef]

31. Liu, J.; Mu, T.; Sun, H.; Fauconnier, M.L. Optimization of ultrasonic-microwave synergistic extraction of flavonoids from sweet potato leaves by response surface methodology. J. Food Process Preserv. 2019, 43, e13928. [CrossRef]

32. Dahmoune, F.; Spigno, G.; Moussi, K.; Remin, H.; Cherbal, A.; Madani, K. Pistacia lentiscus leaves as a source of phenolic compounds: Microwave-assisted extraction optimized and compared with ultrasound-assisted and conventional solvent extraction. Ind. Crop. Prod. 2014, 61, 31-40. [CrossRef]

33. Prommuak, C.; De-Eknamkul, W.; Shotipruk, A.; Shotipruk, A. Extraction of flavonoids and carotenoids from Thai silk waste and antioxidant activity of extracts. Sep. Purif. Technol. 2008, 62, 444-448. [CrossRef]

34. Guo, X.; Zou, X.; Sun, M. Optimization of extraction process by response surface methodology and preliminary characterization of polysaccharides from Phellinus igniarius. Carbohydr. Polym. 2010, 80, 344-349. [CrossRef]

35. Feng, S.; Luo, Z.; Tao, B.; Chen, C. Ultrasonic-assisted extraction and purification of phenolic compounds from sugarcane (Saccharum officinarum L.) rinds. LWT Food Sci. Technol. 2015, 60, 970-976. [CrossRef] 
36. Chemat, F.; Rombaut, N.; Sicaire, A.G.; Meullemiestre, A.; Fabiano-Tixier, A.S.; Abert-Vian, M. Ultrasound assisted extraction of food and natural products. Mechanisms, techniques, combinations, protocols and applications. A review. Ultrason. Sonochem. 2017, 34, 540-560. [CrossRef]

37. Clarke, G.; Ting, K.; Wiart, C.; Fry, J. High correlation of 2, 2-diphenyl-1-picrylhydrazyl (DPPH) radical scavenging, ferric reducing activity potential and total phenolics content indicates redundancy in use of all three assays to screen for antioxidant activity of extracts of plants from the Malaysian rainforest. Antioxidants 2013, 2, 1-10.

38. Madsen, H.L.; Andersen, C.M.; Jørgensen, L.V.; Skibsted, L.H. Radical scavenging by dietary flavonoids. A kinetic study of antioxidant efficiencies. Eur. Food Res. Technol. 2000, 211, 240-246. [CrossRef]

39. Re, R.; Pellegrini, N.; Proteggente, A.; Pannala, A.; Yang, M.; Rice-Evans, C. Antioxidant activity applying an improved ABTS radical cation decolorization assay. Free Radic. Biol. Med. 1999, 26, 1231-1237. [CrossRef]

40. Pacher, P.; Beckman, J.S.; Liaudet, L. Nitric oxide and peroxynitrite in health and disease. Physiol. Rev. 2007, 87, 315-424. [CrossRef]

41. Vanacker, S.A.B.E.; Tromp, M.N.J.L.; Haenen, G.R.M.M.; Vandervijgh, W.J.F.; Bast, A. Flavonoids as scavengers of nitric oxide radical. Biochem. Biophys. Res. Commun. 1995, 214, 755-759. [CrossRef] [PubMed]

42. Gülçin, İ. Antioxidant activity of caffeic acid (3, 4-dihydroxycinnamic acid). Toxicology 2006, 217, $213-220$. [CrossRef] [PubMed]

(C) 2019 by the authors. Licensee MDPI, Basel, Switzerland. This article is an open access article distributed under the terms and conditions of the Creative Commons Attribution (CC BY) license (http://creativecommons.org/licenses/by/4.0/). 